\title{
An Adaptive Architecture for Long Term Energy Programme Management
}

\author{
Ovidiu Noran* \\ IIIS Centre for Enterprise Architecture Research and Management, Griffith University, Queensland, Australia
}

\begin{abstract}
Climate change, population growth, changing energy consumption patterns and the advent of feasible renewable energy sources has prompted governments worldwide to set targets for carbon emission reductions. The transition to a 'near zero emissions' industry and energy production presents significant opportunities but also caveats in relation to maintaining the balance of the 'energy triangle' aspects, namely economic, security and environmental. Various regions and countries find themselves in different economic, cultural and geopolitical situations which require customised approaches. Moreover, the transition is likely to take significant time, with disruptive technologies emerging in the meantime; therefore, a purely technical solution is unlikely to be viable in the long run. Hence, it would be helpful to complement the supportive, albeit high-level artefacts developed by various global organisations with strategic plans satisfying and abiding by principles that maximise the chances of success. Importantly, such strategic planning must follow a method that is transferable between geographical regions and their local maturity levels in respect to energy triangle viewpoints. This paper describes challenges and highlights of planning such a strategy, including guiding principles for the solution architecture and dynamic business models describing the possible structure and relations between an energy transition programme and its projects.
\end{abstract}

\section{Introduction}

A range of important factors such as climate change, population growth, changing energy consumption patterns and the emergence of feasible renewable energy sources has prompted governments worldwide to set targets for carbon emission reductions and consequently, energy efficiency and use of renewable energy. The achievement of such targets presents significant opportunities but also caveats in relation to maintaining the balance of the economic, security and environmental (Umbach's 'energy triangle' [1]) aspects.

The challenges ahead are beyond individual governments; however, while global climate agreements are defined and adhered to, various regions and countries exist in different economic, cultural and geopolitical situations which require customised approaches. Global organisations such as the World Economic Forum (WEF) have worked towards enabling worldwide communication and readiness tools to guide local energy transition decision-making. However, this transition is likely to take significant time, sufficient for new and disruptive technologies to emerge; therefore, it is not advisable to design a purely technical solution that would not be viable in the long run. However, in view of past project failures stemming from the lack of adequate strategic guidance for the involved stakeholders, it would be helpful to build on- and complement the helpful, albeit high-level artefacts developed by the aforesaid global organisations with strategic plans that satisfy and abide by principles that maximise the chances of success in view of the expected extensive length of such transitions. It must be noted however that such strategic planning must follow a method that is transferable between geographical regions and their maturity levels in respect to the local aspects of the 'energy triangle'.

The purpose of this paper is to facilitate the role of strategic management consultancy, with the view of analysing the situation and giving recommendations for particular, locally suitable strategies to implement highlevel energy transition directives. Following an analysis emphasizing strengths, weaknesses, opportunities and threats from political, economic, social, environmental and legal viewpoints, the paper identifies the relevant participating entities in the energy transition challenge.

This is followed by a description of a business concept outlining the vision of an agile business architecture featuring adequate preparedness to adapt itself to changes in the socio-technical environment according to the evolution of the future energy market. Next, the paper performs analyses supporting strategic advice for handling the transition, followed by detailing the strategy to implement the vision, including goals and objectives and the policies and principles that should guide this transformation. Subsequently, the paper describes, using dynamic business models with a subsequent concrete temporal adaptation, how a transition plan can be derived from the present business architecture towards the envisioned future state.

Corresponding author: O.Noran@griffith.edu.au 


\section{The Energy Transition Context}

Discovery of new energy sources and inherent transition have been present throughout the history of mankind. Nowadays, the concept of energy transition comprises fossil sources such as biomass, coal, oil, gas and nuclear giving way to renewables, increasingly adopted as climate change and air quality become stringent issues. Thus, for example the European Parliament has agreed to raise the share of renewable energy to $35 \%$ of the European Union's energy mix by 2030, while promoting a highly energy efficient and renewables-based energy system [2, 3]; for 2050, the share of High Renewable Energy Sources is to reach $75 \%$. Another example is Australia, where the local branch of the International Renewable Energy Agency's Energy Transitions Working Group [4] aims to define a transition plan for Australia's national energy grid from fossil fuel-based to renewable energy so as to reach zero $\mathrm{CO}_{2}$ emissions by 2050 while applying Systems Engineering lifecycle practices [5]. It must be noted that although transitioning to sustainable energy will cause an increasing decline in fossil fuel use, this type of fuel will continue to feature prominently in the energy mix strategies of many countries for a significant time [4].

Generic solutions providing worldwide collaboration, readiness tools [6] and roadmaps [7] to guide local energy transition decision-making have been developed; however, it is recognised that there is a multitude of potential strategies that may apply depending on the level of economic development and existing energy infrastructure [8]. In addition, it is increasingly likely that transition will not be a linear or straightforward process due to a) a series of emerging 'game changers' (such as Internet of Things, mobility transformation, energy system fragmentation [9]) that can significantly disrupt transition and put it on a more unpredictable path [10] and b) potential 'accelerators' that can hasten transition in certain conditions [11]. Finally, technology is evolving in exponentially providing additional disruption and intricacy to what is already emerging as an increasingly complex energy System of Systems.

In the opinion of the author, all of the above unequivocally emphasizes the need for adequate strategies based on flexible methods and architectures that can adapt to the local conditions in space and time, so as to continuously provide the necessary short-term steps to keep to a stable long-term change path.

\subsection{Context Analysis.}

The SWOT [12] technique can be used here to depict high level images of the present and future states. These can subsequently be combined in order to define principles underlying the strategies for a controlled and adaptable transition to the desired future state. Importantly, the SWOT elements must be scoped at least from the above-mentioned economic, security and environment points of view and of course the specific setting. For example, a present strength for a country or area could be the presence of fossil fuel resources; this could be used to finance the transition but could also dampen the appetite and apparent urgency for energy transition locally and abroad while also merely shifting the pollution problem elsewhere (for example, exporting coal, oil and/or natural gas to other regions). Such a strength could however be counteracted by a weakness, such as the lack of processing capabilities (e.g. raw oil resources in the absence of refineries [13]).

Another strength could be the presence of the necessary conditions for specific renewable energy production, i.e. large periods of sunshine and/or wind, geothermal, wave or biomass (or other usable waste [14]) etc. In turn, this can be counteracted by weaknesses exacerbated by the absence of suitable strategies: the lack of transmission infrastructure (so energy can reach the consumers) particularly in the case of large territories (e.g. Australia), possibly complicated by security aspects (e.g. foreign ownership of essential infrastructure [15]). A current weakness of renewable energy generation is also the current difficulty to store energy, essential for some technologies (e.g. solar, wind etc.), with possible solutions such as pumped hydro energy, concentrated solar power and hydrogen storage, established in some regions but with varying degrees of adoption [16] or in their infancy and needing adequate infrastructure [17].

Opportunities can be (besides the obvious effects such as air quality improvement and slowing of climate change) e.g. eliminating fuel dependency (with ensuing beneficial economic and security effects), innovation and creation of new capabilities and skills in building renewable energy generation infrastructure which can also be exported, etc.

Unfortunately a significant number of threats are present as well, such as an improperly planned transition mainly driven by technology and economics, resulting in significant turbulence, redundancy, ill-effects on local communities, compromised concept of renewable energy, black-outs and erratic prices, uncontrollable population switch to small scale local renewable energy generation often using low quality equipment presenting hazards to the grid (e.g. by unsuitable injection of power) and even to human life and property. In this context, the concept of fair, socially acceptable and sustainable transition is gaining momentum, underpinned by the need for long term flexible policies that inspire industry confidence to invest in renewable energy technology, infrastructure and not least re-skilling of personnel affected by the transition [4, 18].

The above-defined aspects are of course all related: for example a present weakness can trigger a future threat. Energy security for example is gaining new dimensions in the context of the transition to renewable energy: from having resilient production capacity complimented by some stock suitable to cover short term outages (which is in fact still a problem for some countries, also affecting their national security $[13,19])$ to being able to transition while maintaining continuity of supply and a stable state of the supply network [20].

Combining SWOT elements (defining opportunities to build on strengths to overcome weakness and thus mitigate threats) may help fleshing out high level directions for energy transition strategies For example, 
opportunities to overcome weaknesses may be exemplified by growing a renewable energy sector to reduce and replace a dependency of energy imports and thus avoid a potential threat - however this would depend on the existence of energy-related strengths as previously defined.

\section{Transition Strategy Analysis}

Relevant literature contains numerous high quality studies published on this topic, outlining policy options and their quantitative consequences, so as to inform governments about what strategies would be suitable to achieve the energy transition goals [11] and to investigate the options and their effects on economy and society [21]. The following outlines a synthesis of the most important aspects of such studies, which must be used in order to guide proper modelling of the energy transition planning.

\subsection{Vision}

The current vision is expressed by the 2015 Paris Climate Agreement, which supports the goal of global warming below $1.5^{\circ} \mathrm{C}$ by 2100 with a more than $50 \%$ chance [22]. This translates in various specific targets for the signatories. For example in Australia energy and industry $\mathrm{CO}_{2}$ emissions are supposed to be nil by 2050 [23] (note the role of so-called credits rolled from the previous agreements in allowing some countries to lag).

\subsection{Readiness}

The 'energy triangle' (economic development and growth, environmental sustainability and energy security and access) viewpoints can be aggregated into an 'energy performance / transition matrix' characterising given economic areas or countries [6] (see Fig. 2). This emphasizes the relation between current performance in relation to energy delivery and future transition preparedness and should be considered in the energy transition strategy planning.

\subsection{Stakeholders Position}

During the ensuing industry transformation, the standing of important stakeholders is likely to shift significantly. This must be taken into account in the proposed transition modelling (which allows for such changes as further detailed in Section 4). Thus, for example the influence of the industry supporting current fossil fuel use and production (e.g. domestic mining industry) may eventually subside. Significant reduction in domestic use of hydrocarbons may also trigger unpredictability of the fossil fuel stakeholders' position on the international market, e.g. with reduction of prices internationally likely to affect domestic producers.

The transition will trigger an increase in renewable energy building and engineering and production market opportunities, which however will require adequately trained workforce (which will take time and needing to be started as soon as possible).

Another important aspect is the technology-enabled decentralization of energy sources and digitalization which will allow traditional consumers to change their role in the energy system (e.g. becoming prosumers [6]).

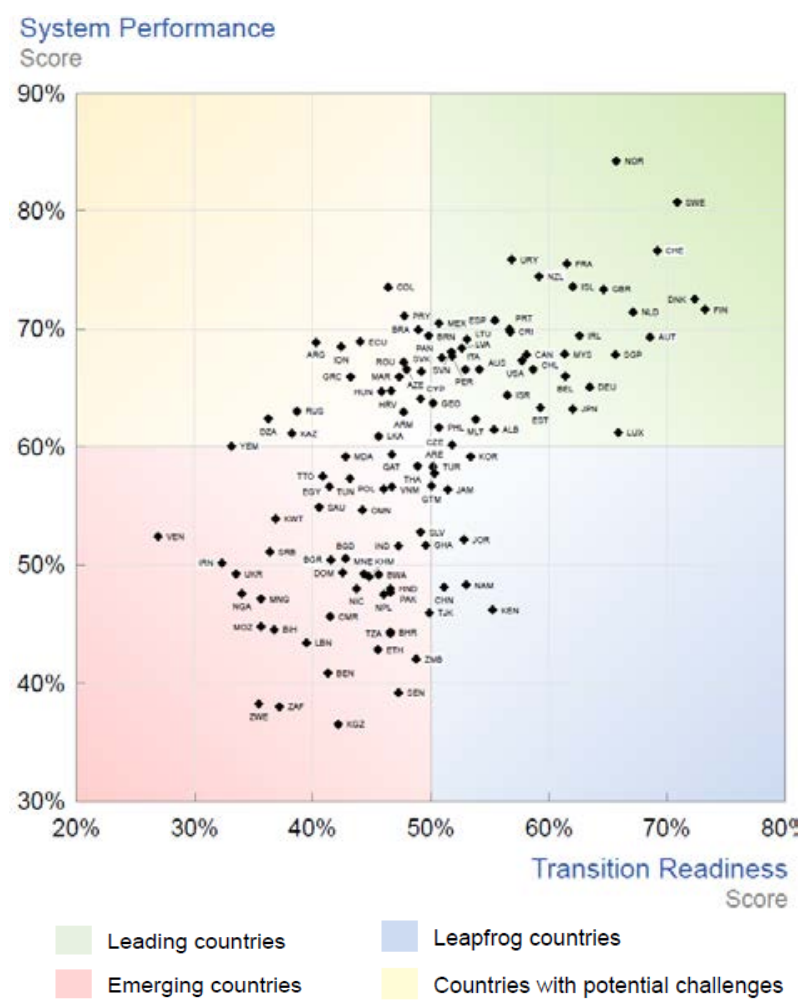

Fig. 1 Energy Transition Matrix [6]

\subsection{Transition Programmes}

The transition is likely to take a long time; therefore, several projects and programmes need to be implemented in parallel, such as:

- Introduction of new standards and legislation for renewable energy production;

- Changes to fossil fuel industry legislation;

- Building of demonstrators of various technologies in parallel to foster innovation;

- Building new renewable energy stations as technologies mature;

- Shutdown and dismantling or transformation / refurbishment of conventional energy stations;

- Renovation of the energy infrastructure (e.g. electricity networks).

To reduce turbulence, influential stakeholders may also choose to encourage and / or effect the implementation of technology transition through solutions with shorter life expectancy, which however produce predictable returns for public and private investors.

\subsection{Extended Analyses}

The following performs further analysis of the aspects deemed essential to the transition planning, using the 
PESTEL [24] technique enriched with aspects deemed to be of high relevance to the energy transition endeavour.

\subsubsection{Political, Risk and Legal Analysis}

Political support for transition is crucial. The lack of political will ranges from 'not being bound' by, or withdrawing from agreements [22], to using various mechanisms (e.g. 'credits') to avoid achieving targets. Unfortunately this is reflected in the lack of suitable policies and non-existent or sub-optimal legislation and strategy leading to chaotic, market-led transition, which is a major threat as previously detailed. Other possible aspects are the political 'myopia' [25] and ambiguity used in defining targets and policies [26], intense lobbying from fossil fuel industries or populist, strong tradition in using non-renewable resources (Japan). The approach to energy transition needs to be bi-partisan however this is not a trivial achievement in view of the above elements and frequent politicisation of the issue.

A major risk to the energy transition is the business uncertainty both for energy producers (future viability) and consumers (energy security). It is unlikely, at least initially, that global solutions will emerge that work for the entire country - especially due to the big differences between highly populated urban- and rural areas. This also points to a heterogeneous solution in the future.

Communities that depend on current $\mathrm{CO}_{2}$ emitting power generators are likely to politically oppose the transition to other energy sources unless appropriate measures are designed and implemented.

Passing suitable laws may take considerable time and approaches and appetite for driving change may radically change with various governments. Intellectual property protection (for new technologies) and waste disposal laws may also affect energy transition.

\subsubsection{Economic Analysis}

One important aspect of the energy transition is the economics. A clear message from various studies (see e.g.[21]) is that the desired energy transition is not feasible unless parallel, rather than sequential adoption of technologies is adopted. This needs appropriate regulatory response, so as to create a level market for upcoming technologies and therefore foster development of multiple fronts. Aspects such as the economic impact of transition to renewable energy on industry and households in respect to the actual emissions reductions must also be considered. For countries whose impact on emissions reduction is small and the economic consequences of an abrupt or sequential transition are dire the parallel approach mentioned above may be best in order to also avoid strong adverse advertising and resulting skewed public opinion [27].

\subsubsection{Social, Resource and Capabilities Analysis}

In most regions, the current energy production and transport market is still coal and gas based, and this is also reflected in the mix of skilled workforce and support companies (engineering, building, maintenance). In some areas, entire communities depend on a local coal / gas power station. Therefore, development and transition of the skill base (e.g. by locally provided retraining) would be necessary, for skills in the technical areas (technicians, engineers) but also in management.

The potential for implementing a fast enough change is hinging on human resources availability (in numbers and in skill). The strategy needs to ensure that specific training and education (which has a long timeframe) urgently addresses the skilled workers shortage and that the plan is favouring the support of local communities

A serious limit of growth for the renewable energy market is the ability for the new industries to develop; this is a main reason for the necessity to adopt the parallel rather than sequential model.

\subsubsection{Technology and Environment Analysis}

Currently there is a range of viable renewable energy technologies available, each best suited (or in combinations) for particular environmental (climate, geography, weather) conditions. For example, in Australia Concentrating Solar Thermal (CST) Power and Wind Power could provide $60 \%$ and $40 \%$ of the total energy mix respectively, being the most cost effective, commercially available, and scalable technologies [28]. Therefore, there may be a strong incentive to focus on specific technologies best suited locally.

However, with technology advancements especially in the storage of electrical energy (e.g. pumped hydro, initially even using contaminated water from former mining sites where applicable), caution should be exercised so as not to create a too homogeneous system, which is then hard to change in the future.

Therefore, WEF [6] for example advises that economies would be best adopting a mix of technologies or approaches to energy transition depending on their readiness and other factors such as existing local infrastructure, engineering capabilities, skills / expertise, institutional support, social and political support and finance. One last factor to consider is climate change itself which can lead to changes in the suitability of particular technologies.

\subsection{Strategic Principles}

It is important that strategic policies and principles are defined and adhered to in the long term in order to guide the transformation processes.

Strategic policies (possibly legislated) can be used to create a level of stability and certainty in investors and current market players that foster the transition and lower risk. For example Mallon and Hughes [21] propose that differential pricing can be used to ensure that less mature technologies get a chance to develop in time, otherwise some sub-optimal technologies (that are most competitive today) can distort long term investment and create undesirable lock-in.

Strategic principles on the other hand, can be defined within the long term policy framework so as investment 
bodies can assess proposed solutions against them and evaluate solution suitability from multiple viewpoints.

A comprehensive list of strategic policies and principles for this purpose is beyond the scope of the present paper. However, due to the importance of this aspect, Table 2 presents a few types that were deemed essential and thus should be considered in any energy transition initiative.

Table 1. Energy transition strategic policy and principle types

- Stakeholder relationship management;;

- Technology;

- Organisational and human resource ;

- Management;

- Investment / financial management / efficiency related (contestability);

- Quality (service delivery quality, accountability, auditability);

- Risk management;

- National security - related (sovereign capability to design, build, operate, maintain and manage);

- Systemic properties ('ilities'), including energy security, availability, resilience, safety, maintainability, modifiability, etc.

\section{Transition Planning}

Historically, energy systems have been developed component-wise rather than in an integrated manner. Blackburn [29] draws an analogy between Defence and Energy approaches by using the Generations Concept, whereby the latest $\left(5^{\text {th }}\right)$ attempts to adopt an integrated Systems of Systems [30] approach. This analogy is clearly warranted, as national security (based also on an operational Defence) is intimately linked to economic and energy security and as such, proposed strategies should promote their co-evolution [31].

Another essential aspect in designing the future energy structure is the need for a system aiming to control a particular environment to match its variety [32]; hence the transition projects and master plan must create an energy future state matching the complexity of the energy transition universe of discourse.

Finally, in designing the future integrated System of Systems structure, it is essential to understand how the life cycles of contributing systems relate to one another. There are two fundamental types of relationships in this regard: 1) Operational relationships that allow multiple systems (under separate control) to cooperate to fulfil a joint mission (in this case, the mandated functions of the energy system, together with necessary non-functional requirements) and 2) Relationships through which the participating systems and the socio-technical environment influence each other's evolution in time.

\subsection{Modelling Energy Transition Planning}

The following presents a way to organise actors' actions and roles in a long term transition plan in view of established strategic goals.

Thus, any system (entity) of interest may be modelled on various levels of abstraction, as deemed necessary in the life-cycle of that system. One can associate with every such level, a 'phase' (set of activity types) necessary to develop these models and their descriptions. This paper makes use of ISO15704's [33] reference architecture modelling framework constructs featuring inherent lifecycle phase representations in order to represent perspectives reflecting concerns and abstractions shared by stakeholder types. This modelling construct differentiates between the mission fulfilment and the management and control tasks of a system, whether partially or fully automated (see Fig. 1).

This high level view abstracts from the flow of time; instead, it represents the fact that various aspects of the entity of interest must be defined by some stakeholders. Note that if the stakeholders are all internal then the entity of interest is able to completely (re)design itself and management is in full control of the entity's destiny.

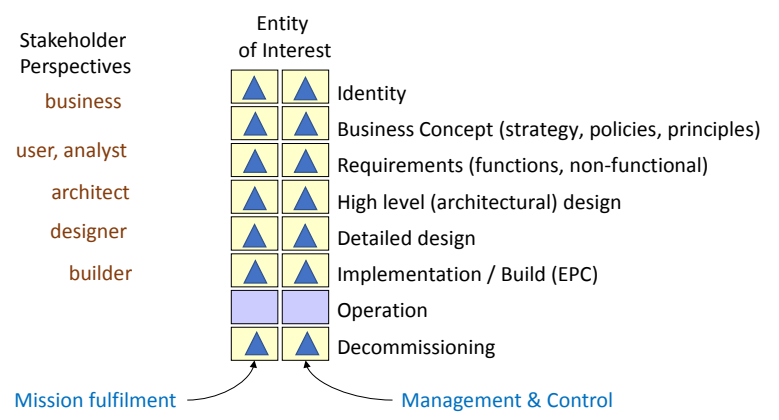

Fig. 2 Modelling Construct used (based on [33]

Alas, more often than not, this redesign capability (reflected in the entity's agility [34]) is limited or nonexistent, as the management of the entity has multiple constraints - for example policies and laws, internal or external resource limitations, etc. Therefore, one must represent the responsibilities and authorities reflecting how one entity influences (or dictates) one or more of these aspects of another entity. The range and role of the various instruments available must be understood to ensure the feasibility of a long term energy transition strategy and plan.

\subsection{Relevant Entities in Transition Planning}

The development of a sound strategy requires detailed analysis of the relationships among stakeholders, in order to understand their short- and long term interests. This is because energy transition can and will have substantial effect on these relationships, and thus they must be managed by policies as well as legal instruments that go beyond the economic aspect. Table 1 lists typical stakeholders of Energy Transition.

Table 2. Energy Market Stakeholders (based on [35])

National Electricity Market (NEM) supervised and operated by the:

- National Energy Regulator of the wholesale electricity and gas markets. In some countries, part of 'Competition and Consumer Commissions', enforcing the rules established by Energy Market Commissions.

- Energy Market Commission, for policy and market 


\section{development;}

- Energy Market Operator market, operational, development and planning functions. Typically it manages the National Electricity Market.

- Energy Delivery: Energy Transport (trunk) and Infrastructure (local), Maintenance and Renewal of energy transport.

- Energy Retailers.

Local Governments Energy Council leads NEM reform and strategic development and also reviews and provides governance of the NEM.

Federal Government, including (a national branch of) International Renewable Energy Agency (IRENA)

Consumers (Industry, Transport, Agriculture, Defence, Households)

Energy Producers (Mining, Oil, Gas, Coal; Renewable energy producers (hydro, solar, wind, geothermal, etc.;

Communities (supporting the current energy industry)

Local Government (legislation, taxation, export regulation)

Investors (individual, corporate, domestic / foreign...)

\subsection{Dynamic Business Models}

As previously mentioned, it is important that the transition plan adapts to changes in the environment and is customisable for the various local conditions. In this sense, it is imperative that the entire life cycles of all relevant entities are taken into account rather than just their current state. Therefore, the paper makes use of the modelling construct previously defined in Section 4.1 (see Fig. 1) to create a 'dynamic business model' representing life cycle relationships underlying a transition plan from the present business architecture towards the envisioned future state.

The approach taken below is based on the metamethodology (a method to create particular methods for specific projects) described in [36] and the principles shown in [37]. The first step is identifying entities of interest, which has been accomplished already in Section 4.2 and Table 1. These entities are then represented using the modelling construct defined in Section 4.1 and Fig. 1, as depicted in Fig. 3.

As can be seen in the above-mentioned figure, the mechanism to coordinate the multiple projects involved in energy transition is in the hands of a Transition Programme that makes decisions on supporting and coordinating them as they make changes to the National Energy Market (NEM) participants. The main role of the Transition Programme is to coordinate and synchronise the investment, which is typically based on publicprivate partnerships.

Next, one uses the extended analyses performed in Section 3.5 in order to determine any necessary additions to the set of entities and to identify the relations between them in the context of their life cycles. These relations are represented using arrows such as shown in Fig. 3 and Fig. 4, more specifically depicting the role of an entity in one or several life cycle phases of another entity (note that all arrows originate in Operation life cycle phases as only operating entities can influence other entities).

For example, Fig. 3 shows that Regulators define the policies that underpin the operation of the NEM and support the principles that must guide the development of individual transformations.

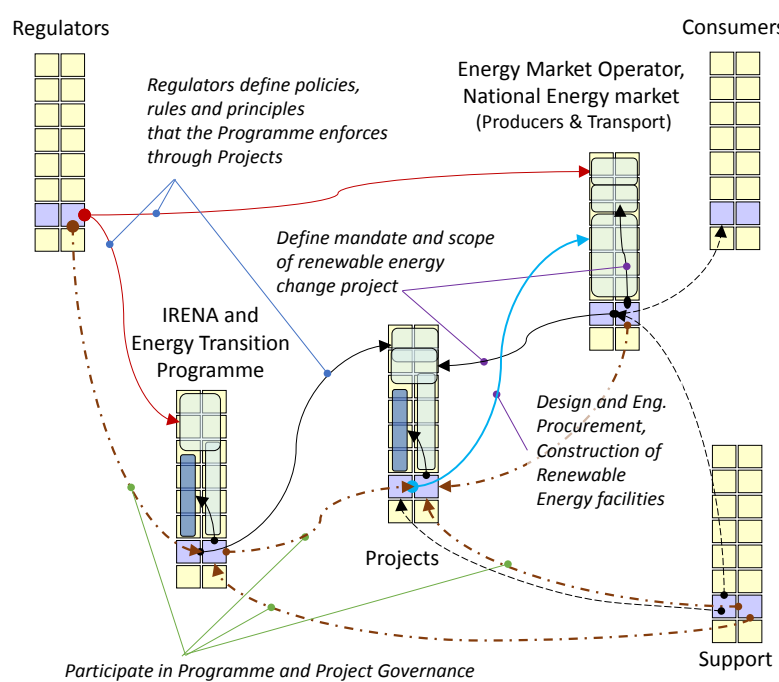

Fig. 3 Coordination of the application of policies and principles

These policies and principles are also guiding the Transition Programme and Projects, similar to how building codes and similar instruments are used to regulate town planning and building projects transformations (see the 'definition' arrows in Fig. 3).

Operational interactions between the Regulators, Programme and Projects represent the participation in Programme and Project governance, including the assessment of project proposals against the above policies and principles (see the 'participate' arrows in Fig. 3). The figure also represents how the project set up by the Transition programme influences the redesign of the entities within NEM.

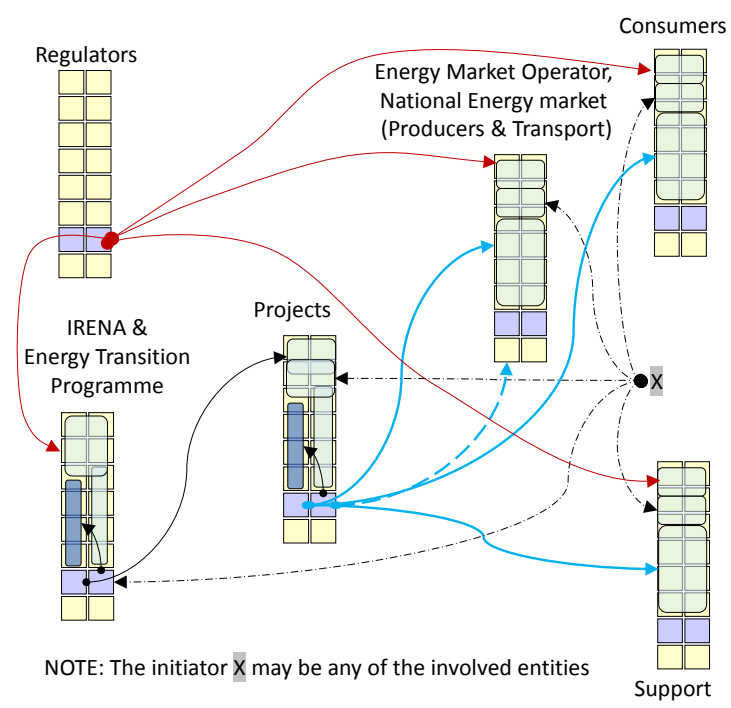

Fig. 4 Multiple synchronised Projects

Figure 4 shows that often, multiple change Projects (including decommissioning) need to run. This is due to the fact that than one entity must simultaneously change. Additional detail includes the representation of the roles of projects in making actual changes to NEM entities, including consumer infrastructure and the representation 
of the supporting entities that also need to change (new capabilities to be developed, specific training to be performed, etc.). These dynamic business models allow reasoning in regards to the influences present and / or input required from other entities for conceiving, designing, creating and operating the entity of interest, such as the Projects set up by the Transition programme and even the Transition Programme itself.

Once the life-cycle relationships between the participating entities have been defined to the necessary degree of detail, the next step can be taken. This involves mapping the previous models onto a GANTT-like model that takes time into account, thus representing the life history [33] of the changing entities, as shown in Fig. 5.

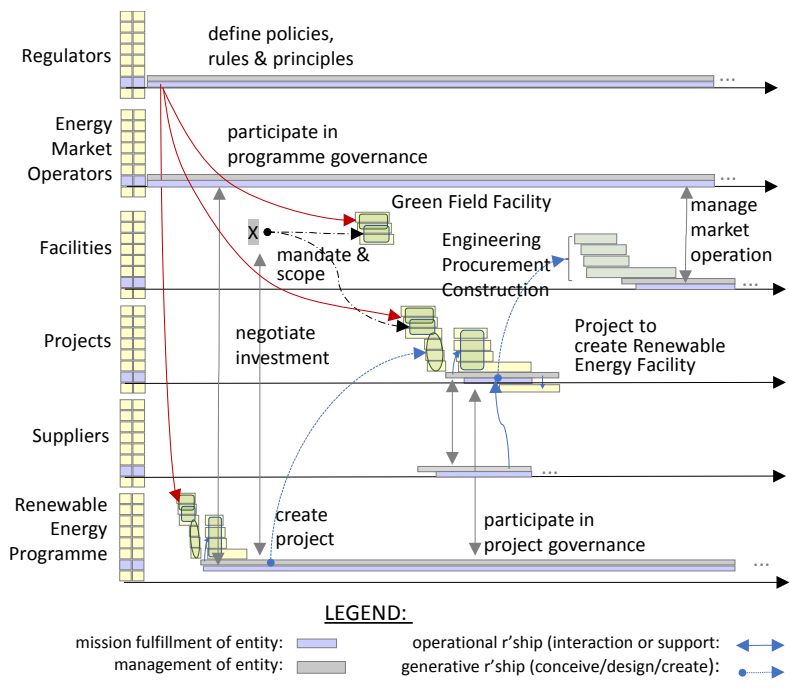

Fig. 5 Representing parallel life histories of entities of interest (Illustration of a greenfield Renewable Energy Facility)

As can be seen in the figure, the various tasks (thin rectangles) are mapped onto the life cycles of the participating entities (on the left hand side), thus allowing to effectively represent the parallel projects involved, including the operational (interaction or support) and generative (conceive, design or create) relationships between the participating entities. From this point on, typical project management of the parallel projects involved in energy transition can proceed.

\subsection{Discussion}

The relevant literature proposes a myriad of approaches to energy transition strategic planning. Therefore, at this point the reader may ask: what is so special about the approach herewith described? There are several important aspects of considering energy in this way:

- The Energy Transition Programme has the authority to enforce global policies and principles, and thus evaluate a suite of projects rather than simply applying these on a project-by-project basis. For example, some forms of renewable energy transformation (e.g. transport) require having the associated infrastructure projects in place;

- The Programme can apply investment strategies (especially in public-private alliances) fostering parallel development of multiple technologies. This is essential due to typical local industry growth limitations [21];
- Organising the Energy Transition Programme in this manner can avoid purely local-based economic investment decisions that would be detrimental to national level social, security and economic interests;

- Taking into account the life cycles of the participating stakeholders and of other relevant entities in the manner shown allows performing long-term planning due to the adaptable nature of the model;

- This is a generic approach that can be adapted to and instantiated for local conditions, as it only provides a framework that can be used by individual countries or areas to plan their own renewable energy transition.

\section{Conclusions and Further Work}

Energy systems are changing at an increasing rate owing to technology innovation, changes in consumer patterns and supply dynamics and the need to address climate change. An effective energy transition comprising a controlled shift towards integrated sustainable, affordable and secure energy systems must be supported by adequate long term strategic planning that is resilient in the face of the various disruptors likely to emerge.

Along these lines, this paper has presented the principles of an adaptive architecture for long term energy programme management which aims to deliver a method transferable between geographical regions and local maturity levels in respect to the 'energy triangle' paradigm. The description of challenges and highlights of such strategy planning has included guiding principles for the solution architecture using SWOT and PESTEL techniques. This was followed by the use of dynamic business models and a sample parallel life histories diagram describing the possible structure and relations between an energy transition programme and its projects.

Further work will seek to validate and further develop the approach presented by testing it in specific local scenarios featuring various levels of complexity so as to enable proper triangulation.

\section{References}

1. F. Umbach, The intersection of climate protection policies and energy security. Journal of Transatlantic Studies. 10(4): p. 374-387, (2012)

2. European Commission. Energy Efficiency Directive. https://ec.europa.eu/energy/en/topics/energyefficiency/energy-efficiency-directive, (2018)

3. REHVA. Energy Efficiency Directive Updates. Available from: https://www.rehva.eu/euregulations/energy-efficiency-directive.html, (2018)

4. IEA, Energy Transitions towards Cleaner, more Flexible and Transparent Systems - A report from the International Energy Agency to the G20 Energy Transitions Working Group (ETWG). Buenos Aires, Argentina: International Energy Agency, (2018).

5. M. O'Keefe, Energy transition working group meeting summary. Sys. Eng. Aus. Nwsltr 70, (2015) 
6. WEF, Fostering Effective Energy Transition A FactBased Framework to Support Decision-Making REF 201218. World Economic Forum, (2018).

7. IRENA, Global Energy Transformation: A Roadmap to 2050. Abu Dhabi: International Renewable Energy Agency, (2018).

8. O. Edenhofer et al., IPCC Special Report on Renewable Energy Sources and Climate Change Mitigation. Cambridge, UK; New York, N.Y.: Cambridge University Press, (2011).

9. WEF, Game Changers in the Energy System Emerging Themes Reshaping the Energy Landscape - REF 050117. World Economic Forum, (2017).

10. N. Hughes, N. Strachan, and R. Gross, The structure of uncertainty in future low carbon pathways. Energy Policy. 52: p. 45-54, (2013)

11. IRENA, Opportunities to accelerate national energy transitions through advanced deployment of renewables - A report from the International Renewable Energy Agency (IRENA) to G20 Energy Transitions Working Group (ETWG). Abu Dhabi: International Renewable Energy Agency, (2018).

12. A. Humphrey, SWOT Analysis for Management Consulting. SRI Alumni Newsletter. SRI Int'1 http://www.sri.com/brochures/dec-05.pdf, (2005).

13. J. Blackburn, Australia's Liquid Fuel Security - Part 2. NRMA Motoring Services, (2014).

14. N. Klinghoffer, N. Themelis, and M. Castaldi, Waste to Energy Conversion Technology. Woodhead Pub. Series in Energy. p. 3-14, (2013).

15. Senate Economics References Committee, Foreign Investment Review Framework. Parliament of Australia, (2016).

16. E. Barbour, et al., A review of pumped hydro energy storage development in significant international electricity markets. Renewable and Sustainable Energy Reviews, . 61: p. 421-432, (2016)

17. Hydrogen Council. Hydrogen Scaling Up: A Sustainable Pathway for the Global Energy Transition. http://hydrogencouncil.com/wp-content/ uploads/2017/11/Hydrogen-Scaling-up_Hydrogenuncil_2017.compressed.pdf., (2017) [cited 2019]

18. E. Krick, Ensuring social acceptance of the energy transition. The German government's 'consensus management' strategy. Journal of Environmental Policy \& Planning. 20(1): p. 64-80, (2018)

19. A. Leca, Romania needs a strategy for thermal energy. Management \& Marketing. Challenges for the Knowledge Society. 10(1): p. 3-11, (2015)

20. N. Greet and P. Barnes, The challenge of energy resilience in Australia - Strategic Options for continuity of supply. Australian Strategic Policy Institute, (2017).

21. K. Mallon and M. Hughes, Industrial Constraints and Dislocations to Significant Emissions Reductions by 2050. A report commissioned by WWF-Australia. NSW: Climate Risk, (2008).
22. United Nations Climate Change. The Paris Agreement. Available from: https://unfccc.int/proc ess-and-meetings/the-paris-agreement/what-is-theparis-agreement, (2019)

23. A. Syed, Australian energy projections to 20492050. Canberra, Australia: Bureau of Resources and Energy Economics (BREE), (2012).

24. A. Gillespie, PESTEL analysis of the macroenvironment. Foundations of Economics. U.S.A: Oxford University Press, (2007).

25. R. Kemp, J. Rotmans, and D. Loorbach, Assessing the Dutch Energy Transition Policy: How Does it Deal with Dilemmas of Managing Transitions? J. of Env. Policy \& Planning. 9(3): p. 315-331, (2007)

26. R. Steurer and C. Clar, The ambiguity of federalism in climate policy-making: how political system in Austria hinders mitigation and facilitates adaptation. J. Env. Pol. \& Plan. 20(2): p. 252-265, (2018)

27. D. Wild. Why Australia must withdraw from the Paris Climate Agreement. https://ipa.org.au/wpcontent/uploads/2018/08/IPA-Report-WhyAustralia-Must-Withdraw-from-Paris.pdf., (2018)

28. P. Hearps and M. Wright, Zero Carbon Australia: Stationary Energy Plan. Melbourne: Melbourne Energy Institute, University of Melbourne, (2010).

29. J. Blackburn, Energy Security: Is there a problem? Australian Defence Magazine. (2018).

30. M.W. Maier, Architecting Principles for System of Systems. Systems Engineering Australia Newsletter. 1(4): p. 267-284, (1998)

31. K. Safarzyńska, K. Frenken, and J.C.J.M. van den Bergh, Evolutionary theorizing and modeling of sustainability transitions. Research Policy. 41(6): p. 1011-1024, (2012)

32. W.R. Ashby, Requisite variety and its implications for the control of complex systems. Cybernetica. 1(2): p. 83-99, (1958)

33. ISO/IEC, Annex A: GERAM, in ISO/IS 15704:2000/Amd1:2005: Industrial automation systems - Requirements for enterprise-reference architectures and methodologies, (2005).

34. R. Dove, Knowledge management, response ability, and the agile enterprise. Journal of Knowledge Management. 3(1): p. 18-35, (1999)

35. Australian Energy Market Operator. National Electricity Market. Available from: https:/www.aemo.com.au/Electricity/NationalElectricity-Market-NEM, (2019)

36. O. Noran, A Meta-methodology for Collaborative Networked Organisations: Creating Directly Applicable Methods for Enterprise Engineering Projects. Saarbrücken: VDM Verlag, (2008).

37. P. Bernus, Planning large scale \& long term industry transformation. Brisbane: Presentation at the Engineers without Borders Convention, (2018). 